\title{
PENERAPAN MODEL PEMBELAJARAN POGIL PADA MATERI LAJU REAKSI UNTUK MELATIHKAN KETERAMPILAN BERPIKIR KRITIS PESERTA DIDIK
}

\section{IMPLEMENTATION OF POGIL MODEL ON RATE OF REACTION TOPIC TO TRAIN STUDENTS CRITICAL THINKING SKILLS}

\author{
Dian Septi Wijiastuti dan *Muchlis
}

Jurusan Kimia FMIPA Universitas Negeri Surabaya

e-mail: muchlis@unesa.ac.id

\begin{abstract}
Abstrak
Tujuan dari penelitian ini ialah untuk mengetahui 1) aktivitas peserta didik yang menunjukkan telah dilatih keterampilan berpikir kritis, 2) keterlaksanaan pembelajaran Process Oriented Guided Inquiry Learning (POGIL), 3) keterampilan dalam berpikir kritis peserta didik pada penerapan POGIL. Jenis penelitian yang digunakan pra-eksperimen dengan desain penelitian One Group Pretest-Posttest Design. Subjek dari penelitian ini ialah peserta didik kelas XI di salah satu SMAN Surabaya. Perangkat pembelajaran yang digunakan berupa RPP, Silabus, dan LKPD yang mengacu pada model pembelajaran POGIL. Instrumen penelitian terdiri dari 1) lembar pengamatan aktivitas peserta didik, 2) lembar pengamatan keterlaksanaan POGIL dan 3) lembar pretest dan posttest berupa 5 soal essay keterampilan berpikir kritis. Hasil penelitian menunjukan bahwa terdapat peningkatan keterampilan kritis dalam berfikir sebelum penerapan model POGIL, 1) aktivitas peserta didik sudah menunjukkan telah dilatih keterampilan berpikir kritis dan beraktivitas sesuai sintak POGIL. 2) keterlaksanaan pembelajaran peserta didik sudah baik, hal ini berdasarkan hasil observasi terhadap pertemuan ke-1 dan ke-2 pada pelaksanaan pembelajaran. 3) hasilnya menunjukan pada pretest dan posttest sudah mencapai nilai standar ketuntasan minimal (KKM) yaitu 70. 4) keterampilan berpikir kritis setelah pembelajaran POGIL lebih tinggi dibandingkan sebelum pembelajaran POGIL dibuktikan dari hasil t-test paired sample dengan nilai $\mathrm{t}_{\text {hitung }}$ $(3,690)>t_{\text {tabel }}(0,3246)$. Keterampilan berpikir kritis dapat dilatihkan dengan model pembelajaran POGIL.
\end{abstract}

Kata kunci: Pembelajaran POGIL, Keterampilan Berpikir Kritis, Laju Reaksi

\begin{abstract}
This study aims to determine 1) whether the students 'activities had shown critical thinking skills, 2) the implementation of Process Oriented Learning (POGIL) learning, 3) students' critical thinking skills in implementing POGIL. This type of research used pre-experiment with the research design One Group Pretest-Posttest Design. The subjects of this study were students of class XI MIA 7 at SMAN 8 Surabaya. The learning tools used are in the form of lesson plans, syllabus, and LKPD which refer to the POGIL learning model. The research instrument consisted of 1) student activity observation sheets, 2) POGIL implementation sheets and 3) pretest and posttest sheets in the form of 5 questions of critical thinking skills. The results showed that the increase in critical skills in thinking before the POGIL model, 1) students have shown that students have shown critical thinking skills and activities. 2) the implementation of student learning is good, this is based on the results of observations of the 1st and 2nd meetings in the implementation of learning. 3) shows the results at the pretest and posttest have reached the minimum completeness standard value (KKM), namely 70.4) critical thinking skills after POGIL learning are higher than before POGIL learning as evidenced by the results of the paired sample $t$-test with tcount $(3,690)>t$ table $(0.3246)$.
\end{abstract}

Key words: Process Oriented Guided Inquiry Learning (POGIL) model, Critical Thinking Skills, Rates Reaction 


\section{PENDAHULUAN}

Kimia ialah satu dari sekian banyak mata pelajaran yang diajarkan di Sekolah Menengah Atas (SMA) yang dapat membentuk kemampuan berpikir logis, kritis, kreatif dan inovatif dalam proses pembelajaran [1]. Tujuan pembelajaran kimia untuk mengembangkan keterampilan peserta didik berdasarkan minat, bakat dan kemampuan akademiknya dalam suatu kelompok mata pelajaran ilmiah [2].

Salah satu materi pokok kimia yaitu Laju Reaksi hal ini didasarkan kurikulum 2013, siswa tidak hanya harus berprestasi secara akademis, tetapi juga harus unggul dalam bidang keterampilan sosial. Oleh karena itu peserta didik diharapkan untuk memiliki kemampuan bertanggung jawab kepada lingkungan, kemampuan interpersonal, kemampuan antarpersonal dan kemampuan berpikir kritis. Namun permasalahan yang dihadapi menunjukkan bahwa banyak peserta didik tidak dapat berpikir kritis karena guru tidak dapat mengintegrasikan pemikiran kritis ke dalam praktik pembelajaran setiap hari $[3,4]$.

Fiescher menjelaskan bahwa berpikir kritis merupakan salah satu jenis pemikiran evaluatif, baik kertik maupun berfikir kreatif, dan terutama terikat dengan kualitas ide atau argument yang dikemukakan untuk mendukung suatu [5]. Facione menjelaskan bahwa terdapat 6 komponen dalam berfikir kritis, yaitu: menjelaskan, menganalisis, mengevaluasi, menyimpulkan, menjelaskan dan mengatur diri sendiri [6]. Namun hanya 3 indikator yang diukur dalam penelitian ini yaitu interpretasi, analisis dan inferensi. Dari hasil pra penelitian diketahui tingkat kemampuan dalam berpikir kritis masih tergolong rendah. Pernyataan ini diperkuat dengan hasil wawancara guru kimia bahwa keterampilan berpikir kritis khususnya untuk mata pelajaran kimia belum banyak diterapkan keterampilan tersebut dalam kegiatan belajar. Kritis dalam berfikir dapat dilatihkan dalam pembelajaran sehingga dapat meningkat [7].

Model Pembelajaran POGIL merupakan model pembelajaran yang dapat menyesuaikan dengan karakteristik materi laju reaksi untuk melatih peserta didik dalam mengembangkan kemampuan berfikir kritis. POGIL sendiri di sini merupakan singkatan dari Process Oriented Guided Inquiry Learning. POGIL ialah pendekatan instruksional yang berpusat pada peserta didik maka dari itu dalam kelas atau laboratorium POGIL, siswa bekerja dalam tim kecil dengan guru bertindak sebagai fasilitator [8]. Tim peserta didik menggunakan kegiatan yang dirancang khusus yang umumnya mengikuti paradigma siklus belajar [9]. Aktivitas POGIL dirancang dalam tiga karakteristik utama, yaitu peserta didik bekerja dalam tim dan guru sebagai fasilitator, guru membimbing peserta didik untuk membangun pemahaman melalui eksplorasi, dan memfasilitasi pengembangan keterampilan proses yang kompleks seperti pemikiran tingkat tinggi [10]. Hal kompleks dalam keterampilan pemikiran tingkat tinggi dapat disebut juga sebagai keterampilan berpikir kritis [11].. Berpikir kritis memiliki dua komponen yang mendasarinya, yang pertama adalah sekumpulan informasi dan keterampilan menghasilkan dan memproses kepercayaan. Sedangkan yang kedua adalah sekumpulan infromasi yang memproses suatu kebiasaan [12]. Berpikir kritis tidak hanya berupa sekumpulan informasi, namun juga dapat digunakan untuk mengatur perilaku seseorang. Oleh karena itu berpikir kritis harus dibedakan menjadi: 1) memperoleh dan menyimpan informasi, karena melibatkan cara-cara tertentu utuk menemukan dan menggunakan informasi perolehan dan penyimpanan informasi semata, karena melibatkan cara tertentu di mana informasi dicari dan dipergunakan; 2) seperangkat keterampilan, dikarenakan melibatkan penggunaan yang terus-menerus; dan 3) menggunakan kemampuan kritis dalam berfikir sebagai latihan tanpa menerima hasilnya. [13].

Berpikir kritis dan POGIL memiliki keterkaitan satu sama lain [14]. Berpikir kritis merupakan suatu kemampuan yang harus dimiliki oleh peserta didik dalam pembelajaran kimia agar peserta didik bisa mengambil keputusan yang tepat dalam menyelesaikan masalah dalam pembelajaran kimia [15]. Salah satu materi kimia adalah laju reaksi. Karakteristik materi laju reaksi dianggap mampu melatihkan keterampilan kritis dalam berfikir jika diterapkan model 
pembelajaran POGIL [16]. Pernyataan ini diperkuat dengan data hasil penelitian sebelumnya bahwa dapat meningkatkan keterampilan kritis dalam berpikir sebesar $31 \%$ pada kegiatan preetest menjadi sebesar $76 \%$ pada kegiatan posttest [17]. Farida dan Muchlis menyampaikan bahwa Process Oriented Inquiry Learning (POGIL) ialah model yang menitikberatkan kepada komponen proses dan komponen isi pembelajaran [8]. Model pembelajaran POGIL ialah model pembelajaran berkelompok secara heterogen dengan tujuan peserta didik dalam penguasaan materi dapat ditingkatkan untuk mengembangkan kemampuan berpikir, komunikasi, diskusi, analisa dan evaluasi untuk mewujudkan proses pembelajaran peserta didik dengan benar. Sintaks model pembelajaran POGIL ialah arahan, eksplorasi, penemuan konsep, pengaplikasian, dan penutup [18].

Berdasarkan indikasi di atas, penelitian ini bertujuan untuk mengetahui 1) aktivitas peserta didik yang menunjukkan telah dilatih keterampilan dan aktivitas berpikir kritis sesuai sintak POGIL, 2) keterlaksanaan pembelajaran POGIL, 3) keterampilan kritis dalam berfikir peserta didik pada penerapan model pembelajaran POGIL.

\section{METODE}

Metode yang dipilih peneliti ialah pra eksperimen. Pra eksperimen (one group pretest posttes design) yaitu penelitian yang dilaksanakan tanpa adanya kelas kontrol. Sasaran dalam penelitian ini adalah satu kelas XI MIPA 7 di salah satu SMA Negeri Surabaya tahun ajaran 2020/2021.

\section{$\mathrm{O}_{1} \times \mathrm{O}_{2}$}

Keterangan:

O1 : Skor pretest untuk mengetahui KBK peserta didik yang dilakukan sebelum diterapkan model pembelajaran POGIL materi laju reaksi.

$\mathrm{X}$ : Penerapan model pembelajaran POGIL materi laju reaksi.
$\mathrm{O} 2$ : Skor posttest untuk mengetahui KBK peserta didik yang dilakukan sesudah menerapkan model pembelajaran POGIL materi laju reaksi.

Perangkat pembelajaran yang digunakan adalah RPP, Silabus dan LKS yang mengacu pada pembelajaran POGIL. Pembelajaran dan perangkat pembelajaran dalam penelitian ini mengacu pada 5 indikator POGIL yaitu orientasi, eksplorasi, penemuan konsep, aplikasi, dan closure. Instrumen penelitian yang digunakan berupa soal pretest dan posstest kemampuan berpikir kritis. Instrumen penelitian yang digunakan terdiri atas tes kemampuan berpikir kritis pretest dan posttest terdiri dari 5 soal essay yang mengacu pada indikator keterampilan berpikir kritis yaitu interpretasi, analisis dan inferensi. Perangkat pembelajaran dan instrumen penelitian divalidasi oleh dosen dan guru terlebih dahulu untuk menguji apakah perangkat pembelajaran tersebut sesuai dengan sintaks model pembelajaran POGIL serta sesuai dengan kompetesi inti pada pembelajaran laju reaksi. Sedangkan instrumen penelitian dilakukan validasi oleh dosen ahli sebelum akhirnya diuji validitasnya.

Teknik analisis data pada penelitian ini ialah analisis data keterlaksanaan sintaks POGIL, analisis aktivitas peserta didik, dan analisis tes keterampilan berpikir kritis yang diuji melalui uji hipotesis t-test. Keterlaksanaan sintaks POGIL diamati oleh 3 pengamat sesuai kriteria yang telah ditentukan. Hasil yang diperoleh dari penilaian pengamat diolah menggunakan rumus:

keterlaksanaan $=\frac{\text { jumlah skor yang diperoleh }}{\text { jumlah skor maksimal }} \times 4$

Aktivitas peserta didik selama pembelajaran 2 pertemuan diamati oleh 3 pengamat. Aktivitas peserta didik dapat dikatakan mendukung proses pembelajaran selama dilatihkan keterampilan berpikir kritis jika besarnya persentase aktivitas yang relevan lebih besar dibandingkan dengan persentase aktivitas yang tidak relevan. Aktivitas peserta didik diolah dengan menggunakan rumus: 
$\%$ Aktivitas $=\frac{\sum \text { waktu aktivitas yang muncul }}{\sum \text { aktivitas keseluruhan }} \times 100 \%$

Siswa mendapatkan nilai posttest $\geq 75$ maka dapat dikatakan tuntas. Kemudian untuk mengetahui peningkatan keterampilan berpikir kritis dapat dihitung dengan menggunakan $\mathrm{N}$ Gain dengan rumus:

$$
<\mathrm{g}>=\frac{\text { skor posttest }- \text { skor pretest }}{\text { skor maksimal }- \text { shor pretest }}
$$

Persentase ketuntasan klasikal dapat dihitung dengan menggunakan rumus:

$$
\text { \% Ketuntasan Klasikal }=\frac{\sum \text { siswayang tuntas }}{\sum \text { seluruh siswa }} \times 100 \%
$$

\section{HASIL DAN PEMBAHASAN}

Data penelitian tentang keterampilan berpikir kritis diperoleh dari hasil tes. Setelah memperoleh data, dianalisis dan di interpretasikan sebagai gambaran hasil penelitian. Sebelum soal kemampuan berfikir kritis diujikan, soal tersebut sudah diverifikasi oleh dua validator yang merupakan dosen ahli. Hasil validasi terdapat dalam tabel 1 .

Tabel 1. Hasil Validasi

\begin{tabular}{lll}
\hline No. & \multicolumn{1}{c}{ Aspek } & \multicolumn{1}{c}{ Kriteria } \\
\hline 1. & Silabus & $74 \%$ (valid) \\
2. & RPP & $84 \%$ (sangat \\
& & valid) \\
3. & LKPD & $86 \%$ (sangat \\
& valid) \\
4. & Kisi-Kisi Pretest \& & $78 \%$ (valid) \\
& $\begin{array}{l}\text { Posttest } \\
\text { 5. }\end{array}$ & $87 \%$ (sangat \\
& $\begin{array}{l}\text { Pengamatan Model } \\
\text { Pembelajaran }\end{array}$ & valid) \\
\hline
\end{tabular}

Instrumen soal terdiri dari 5 soal yang mewakili 3 indikator menurut Facione, indikator asli berjumlah 7 indikator namun dalam penelitian ini hanya digunakan sebanyak 3 indikator dengan analisis yang telah dilakukan peneliti bahwa hanya 3 indikator yang mencakup materi yang diajarkan di SMA. Ketiga indikator tersebut adalah interpretasi, analisis, dan inferensi. Pelaksanaan penelitian peserta didik mengerjakan tes kemampuan dalam berpikir kritis yang berjumlah 5 soal essay dengan waktu 90 menit melalui google classroom.

Aktivitas peserta didik pada pembelajaran sudah meningkat dan terlatih untuk kritis dalam berfikir. Hal ini ditunjukkan dari peserta didik yang aktif dalam pelaksanaan belajar mengajar, serta hasil uji kemampuan berpikir kritis meningkat dari rata-rata 75 menjadi 87 , keterlaksanaan dalam arti kualitas guru dalam menerapkan POGIL sudah baik dilihat dari penilaian validasi RPP dimana RPP sudah memenuhi sintaks POGIL dengan hasil validasi sebesar 90\% (sangat valid). 3) keterampilan dalam berpikir kritis, berupa a) interpretasi, analisis dan inferensi diuji menggunakan pretest dan posttest berpikir kritis dan hasil menunjukkan bahwa nilai keduanya sudah mencapai nilai standar ketuntasan minimal (KKM) yaitu 70, dengan ketuntasan klasikal sebesar $80 \%$ [21] sedangkan rata-rata posttest sebesar 87 dengan ketutasan klasikal sebesar 95\%. Rata-rata pretest sebesar 75 sedangkan rata-rata posttest sebesar 87. Dan hasil t-test menunjukkan bahwa nilai t hitung $(3,690)>$ $\mathrm{t}$ tabel (0,3246). Dari hasil tersebut dapat diinterpretasikan bahwa keterampilan berpikir kritis setelah pembelajaran POGIL lebih tinggi dibandingkan keterampilan berpikir kritis sebelum pembelajaran POGIL. Sesuai dengan analisis yang telah dilakukan mengindikasi bahwa kegiatan guru dan siswa pada pelaksanaan pembelajaran menggunakan model POGIL terlaksana dengan baik. Presentase keterlaksanaan proses pembelajaran dengan POGIL terdapat dalam tabel 2.

Berdasarkan tabel 2, rata-rata keterlaksanaan model pembelajaran POGIL meningkat dari dua pertemuan. Dalam pertemuan pertama rata-rata keterlaksanaan model POGIL yaitu $98,61 \%$ dan mengalami peningkatan pada pertemuan kedua dengan rerata sebesar 99,30\%. Hal ini sesuai dengan penelitian yang dilaksnakan oleh Malik yakni, aktivitas guru dan peserta didik semakin meningkat dari pertemuan ke pertemuan selanjutnya [22].

Tahap orientasi dalam model POGIL yang diterapkan dalam kegiatan ini ialah peserta didik diminta untuk menganalogikan sebuah 
fenomena yang diberikan oleh peneliti. Tahap eksplorasi dalam model POGIL yang diterapkan dalam kegiatan penelitian ini ialah, peserta didik dibimbing oleh peneliti untuk menemukan permasalahan, kemudian merumuskan masalah, dan memahami masalah yang terdapat pada lembar kerja peserta didik (LKPD) dan video praktikum yang terdapat di google classroom. Siswa antusias dalam kegiatan ini. Menurut
Ningsih [23] melalui eksperimen terbimbing secara signifikan dapat memperbaiki kemampuan peserta didik untuk memahami argumen dan masalah di dalam kelas. Tahap pembentukan konsep dalam model POGIL yang diterapkan yakni peserta didik mengerjakan soal-soal yang ada didalam menganalisis LKPD dan video praktikum berdasarkan literatur dan sumber lainnya.

Tabel 2. Keterlaksanaan model pembelajaran POGIL

\begin{tabular}{cccc}
\hline No. & Langkah model POGIL & Pertemuan ke $\mathbf{- 1}(\boldsymbol{\%})$ & Pertemuan ke-2 (\%) \\
\hline 1. & Pendahuluan & 100 & 100 \\
2. & Orientasi & 100 & 100 \\
3. & Eksplorasi & 100 & 100 \\
4. & 100 & 100 \\
5. & & 100 \\
6. & Pembentukan konsep & 100 & 95,83 \\
7. & Closure & 91,67 & 99,30 \\
\hline
\end{tabular}

Peserta didik memiliki pengalaman belajar yang memudahkan peserta didik dalam memahami konsep faktor laju reaksi. Hal ini sesuai dengan pandangan Bruner bahwa dalam proses pembelajaran jika peserta didik secara langsung mengalami dan berpartisipasi aktif dalam proses pembelajaran maka peserta didik akan memperoleh pengalaman melalui eksperimen atau model lain yang memungkinkan siswa untuk belajar [24].

Tahap aplikasi yaitu konsep yang telah dibentuk peserta didik di aplikasikan dalam fenomena kehidupan sehari-hari. Dalam hal ini memiliki tujuan agar peserta didik mampu mengaitkan antara konsep dan pengaplikasian konsep dalam kehidupan sehari-hari peserta didik.

Uji prasyarat analisis menggunakan uji normalitas. Uji normalitas dipergunakan untuk mengetahui apakah sebaran data terdistribusi normal atau tidak. Dilihat nilai sigifikan pada kolom Kolmogorov-Smirnov, jika nilai diatas 0,05 data terdistribusi normal, sementara apabila diatas 0,05 maka data tidak terdistribusi normal.
Tabel 3. Tests Of Normality Pretest

\begin{tabular}{lllllll}
\hline \multicolumn{4}{c}{$\begin{array}{l}\text { Kolmogorov- } \\
\text { Smirnov }^{\mathbf{a}}\end{array}$} & \multicolumn{4}{c}{ Shapiro-Wilk } \\
\hline PRE & $\begin{array}{l}\text { Statis } \\
\text { Df }\end{array}$ & Sig. & Statis & Df & Sig \\
TES & tic & & & tic & & \\
T &, 196 & 36 &, 07 &, 859 & 36 &, 01 \\
\hline
\end{tabular}

Tabel 4. Tests Of Normality Pretest

\begin{tabular}{lllllll}
\hline & \multicolumn{3}{c}{$\begin{array}{c}\text { Kolmogorov- } \\
\text { Smirnov }\end{array}$} & \multicolumn{3}{c}{ Shapiro-Wilk } \\
\hline POS & Statis & Df & Sig. & Statis & Df & Sig \\
TES & tic & & & tic & & \\
T &, 157 & 36 &, 09 &, 961 & 36 &, 11 \\
\hline
\end{tabular}

\section{a. Lilliefors Significance Correction}

Tabel 3 mengindikasi bahwa hasil dari uji normalitas pretest didapatkan sig $=0,071>0,05$ maka data pretest terdistribusi normal. Sementara tabel 4 mengindikasi bahwa hasil dari uji normalitas postest didapatkan sig $=0,091>0,05$ oleh sebab itu data posttest terdistribusi normal. 
Tabel 5. Paired Samples Correlations

\begin{tabular}{llll}
\hline & N & Correlation & Sig \\
\hline Pair 1 & 36 &, 883 &, 004 \\
PRETEST \& & & & \\
POSTTEST & & &
\end{tabular}

Uji t yang dipergunakan ialah Uji t-paired untuk membandingkan nilai pretest dan posttest pada kelompok yang sama karena uji t-paired merupakan uji beda atau uji komparatif. Syarat uji t hanya ada satu, yaitu data harus terdistribusi normal. Pada penelitian ini data sudah diujikan dan hasilnya terdistribusi normal

Sesudah uji prasyarat analisis diketahui bahwa data penelitian terindikasi normal, langkah berikutnya ialah melakukan analisis data menggunakan uji t untuk menguji pengaruh model POGIL terhadap kemampuan berpikir kritis peserta didik. Hasil dari perhitungan uji $t$ menggunakan Microsoft Excel disajikan dalam Tabel 6 berikut:

Tabel 6. Paired Samples Test

\begin{tabular}{|c|c|c|c|c|c|c|c|c|}
\hline & \multicolumn{5}{|c|}{ Paired Differences } & \multirow[t]{3}{*}{$\mathrm{T}$} & \multirow[t]{3}{*}{ Df } & \multirow{3}{*}{$\begin{array}{l}\text { Sig. (2- } \\
\text { tailed) }\end{array}$} \\
\hline & \multirow[t]{2}{*}{ Mean } & \multirow[t]{2}{*}{$\begin{array}{l}\text { Std. } \\
\text { Deviation }\end{array}$} & \multirow[t]{2}{*}{$\begin{array}{l}\text { Std. } \\
\text { Eror } \\
\text { Mean }\end{array}$} & $\begin{array}{l}95 \% \\
\text { Interval } \\
\text { Difference }\end{array}$ & $\begin{array}{l}\text { Confidence } \\
\text { of the }\end{array}$ & & & \\
\hline & & & & Lower & Upper & & & \\
\hline $\begin{array}{l}\text { Pair } 1 \\
\text { PRETEST } \\
\text { POSTTEST }\end{array}$ & ,889 & 1,536 & ,589 &,- 085 & 693 & 3,690 & 35 & ,000 \\
\hline
\end{tabular}

Tabel paired sampel test dapat terlihat nilai $t_{\text {hitung }}$ dan dibandingkan dengan $t_{\text {tabel }}$ pada $\mathrm{df}=35$. Hasil menunjukkan bahwa nilai $\mathrm{t}_{\text {hitung }}$ $(3,690)>t_{\text {tabel }}(0,3246)$ yang berarti nilai rata-rata kemampuan berpikir kritis peserta didik setelah diterapkan POGIL lebih besar dibanding sebelum diterapkan pembelajaran POGIL. Hal ini dapat diinterpretasikan bahwa model pembelajaran POGIL dapat meningkatkan kemampuan dalam berpikir kritis peserta didik pada materi laju reaksi.

Keterampilan berpikir kritis yang muncul pada siswa yaitu interpretasi, analisis, dan evaluasi. Peserta didik mampu mengerjakan tes kemampuan berpikir kritis yang terdiri dari 5 soal essay dalam waktu 90 menit melalui google classroom. Dari hasil yang diperoleh nilai posttest lebih tinggi dari nilai pretest. Hal ini sesuai dengan penelitian Prihatami [25], nilai posttest lebih tinggi dari pretest menunjukkan kemampuan berpikir kritis peserta didik yang meningkat.

\section{SIMPULAN}

Berdasarkan hasil dari analisis pada penelitian ini, dapat disimpulkan bahwa model
POGIL dapat meningkatkan keterampilan berpikir kritis siswa dengan rincian sebagai berikut: 1) Aktivitas peserta didik pada pembelajaran sudah meningkat dan terlatih untuk berpikir kritis. Hal ini ditunjukkan dari peserta didik yang aktif dalam pelaksanaan pembelajaran, serta hasil uji kemampuan berpikir kritis meningkat dari ratarata 75 menjadi 87 .

2) Keterlaksanaan model pembelajaran POGIL, guru dalam menerapkan POGIL sudah baik dilihat dari penilaian validasi RPP dimana RPP sudah memenuhi sintaks POGIL dengan hasil validasi sebesar $90 \%$ (sangat valid).

3) Keterampilan berpikir kritis, berupa interpretasi, analisis dan inferensi diuji menggunakan pretest dan posttest berpikir kritis dan hasil menunjukkan bahwa nilai keduanya sudah mencapai nilai standar ketuntasan minimal (KKM) yaitu 70 . Rata-rata pretest sebesar 75 sedangkan rata-rata posttest sebesar 87 . Nilai $\mathrm{t}$ hitung 3,690 lebih besar dari t tabel 0,3246. Hal ini memiliki arti dengan diterapkannya model POGIL dapat melatihkan kemampuan berpikir kritis peserta didik. Sehingga terjadi kecenderungan bahwa ketika diterapkan POGIL 
dapat meningkatkan kemampuan berpikir kritis peserta didik.

\section{DAFTAR PUSTAKA}

1. Elder, Linda; Paul, Richard. 2012. Critical Thinking: Competency Standards Essential to the Cultivation of Intellectual Skills, Part 4. Journal of Developmental Education: Vol 35. No 3, hal. 30-31.

2. Permendikbud. 2014. Peraturan Menteri Pendidikan dan Kebudayaan Republik Indonesia Nomor 59 Tahun 2014 Tentang Kurikulum 2013 Sekolah Menengah Atas/ Madrasah Aliyah. Jakarta: Departemen Pendidikan dan Kebudayaan.

3. Choy, S. C., \& Cheah, P. K. 2009. Teacher perceptions of critical thinking among students and its influence on higher education. International Journal of Teaching and Learning in Higher Education. Vol. 20, No.2, hal. 196-204.

4. Choy, S. C., \& Oo, P. S. 2012. Reflective thinking and teaching practices: a precursor for incorporating critical thinking into the classroom?. International Journal of Instruction. Vol. 5, No.1,hal. 167-182.

5. Fischer, Alec. 2012. Berpikir Kritis Sebuah Pengantar. Jakarta:Erlangga

6. Facione, PeterA. 2011. Critical Thinking: What it is and Why It Counts. Research Gate.

7. Chantaranima, T., \& Yuenyong, C. 2014. The outcomes of teaching and learning about sound based on Science Technology and Society (STS) approach. Procedia Social and Behavioral Sciences. Vol. 116, No. 14, hal 22862292

8. Simonson, S. R. (Ed.). 2019. POGIL: $A n$ introduction to process oriented guided inquiry learning for those who wish to empower learners. Stylus Publishing, LLC.

9. Treagust, D. F., Qureshi, S. S., Vishnumolakala, V. R., Ojeil, J., Mocerino, M., \& Southam, D. C. 2020. Process-oriented guided inquiry learning (POGIL) as a culturally relevant pedagogy $(C R P)$ in Qatar: A perspective from grade 10 chemistry classes. Research in Science Education, Vol.50, No.3, hal. 813-831.

10. DeMatteo, M. P. 2019. Combining POGIL and a Flipped Classroom Methodology in Organic Chemistry. In Active Learning in Organic Chemistry: Implementation and Analysis (pp. 217240). American Chemical Society.

11. Stowe, R. L., \& Cooper, M. M. 2017. Practicing what we preach: assessing "critical thinking" in organic chemistry. Journal of Chemical Education, Vol.94, No.12, hal. 18521859.

12. Suardana, I. N., Redhana, I. W., Sudiatmika, A. A., \& Selamat, I. N. 2018. Students' Critical Thinking Skills in Chemistry Learning Using Local Culture-Based $7 E$ Learning Cycle Model. International Journal of Instruction, Vol. 11, No.2, hal 399-412.

13. Danczak, S. M., Thompson, C. D., \& Overton, T. L. 2017. 'What does the term Critical Thinking mean to you?'A qualitative analysis of chemistry undergraduate, teaching staff and employers' views of critical thinking. Chemistry Education Research and Practice, Vol. 18, No.3, hal. 420-434.

14. Saputro, A. D., Rohaeti, E., \& Prodjosantoso, A. K. 2018. Promoting Critical Thinking and Problem Solving Skills of Preservice Elementary Teachers through Process-Oriented GuidedInquiry Learning (POGIL). International Journal of Instruction, Vol. 11, No. 4.

15. Irwanto, S., \& AD, R. E., \& Prodjosantoso, AK (2018). Promoting critical thinking and problem solving skills of pre-service elementary teachers through processoriented guided-inquiry learning (POGIL). International Journal of Instruction, Vol. 11, No.4, hal. 777-794.

16. Cascolan, H. M. S. (2019). Students' Conceptual Understanding, Metacognitive Awareness and SelfRegulated Learning Strategies Towards Chemistry Using POGIL Approach. ASEAN Multidisciplinary Research Journal, Vol. 1, No.1, hal. 1-12. 
17.Farida, Yayik dan Muchlis. 2017. Implementasi Model Pembelajaran POGIL Untuk Melatihkan Keterampilan Berpikir Kritis yang Memiliki Kemampuan Awal Berbeda pada Materi Laju Reaksi Kelas XI SMAN 1 Pacet Mojokerto.UNESA Journal of Chemistry Education Vol, 6 No 1 pp, 118-124 Januari 2017. Surabaya : Jurusan Kimia FMIPA UNESA

18.Hanson, D.M. 2006. Instructor's Guided Process-Oriented Guided-Inquiry Learning. Lisle: Pasific Crest.

19. Riduwan. 2013. Skala Pengukuran VariabelVariabelPenelitian. Bandung: Alfabeta.

20. Hake, R. R. 1998. Interactive Engagement Versus Traditional Methods : A SixThousand Student Survey of Mechanics Test Data for Introductory Physic Courses. American Journal Physics, Vol. 66, hal. 66-74.

21. Sudjana. 1992. Metode Statistik. Bandung: Tarsito.

22. Malik Adam, Okta Viani, Wahyuni Handayani, dan Muhammad Minan
Chusni. 2017. Penerapan Model Process Oriented Guided Inquiry Learning (POGIL) Untuk meningkatkan Keterampilan Berpikir Kritis Peserta Didik. JPPPF Jurnal Penelitian \& Pengembangan Fisika, Vol 3 No.2.

23. Ningsih, SM, Bambang S, \& Sopyan, A 2012, Implementasi model pembelajaran Process Oriented Guided Inquiry Learning (POGIL) untuk meningkatkan kemampuan berpikir kritis peserta didik. Unnes Physics Education Journal, vol. 1 , no. 2 , hal. 44-52.

24. Bruner. 2012. Investigating optimal learning moments in U.S. and finnish science classes. Journal of Research in Science Teaching.

25. Prihatami, Erlin. 2019. POGIL Berpengaruh terhadap Kemam puan Berpikir Kritis Matematis? Alpha Math Journal of Mathematics Education : Vol 5, No. 2. 